\title{
Bactericidal Activity of Serum By Brucella Abortus RB51 Outer Membrane Protein's Combined By Brucella Abortus $\$ 99$ Lipopolysaccharide Induction
}

\section{Adeleh Attar}

Zanjan University of Medical Sciences

Hamed Afkhami

Shahed University Faculty of Medical Sciences

Mansoor Khaledi

Shahed University Faculty of Medical Sciences

Mahdi S.Sadati ( $\nabla$ h.a.university.ac@gmail.com )

Islamic Azad University Tehran North Branch

\section{Research Article}

Keywords: Brucella abortus RB51, Bactericidal activity, Brucella abortus S99, Outer Membrane Protein's

Posted Date: February 19th, 2021

DOl: https://doi.org/10.21203/rs.3.rs-231416/v1

License: (9) This work is licensed under a Creative Commons Attribution 4.0 International License. Read Full License 


\section{Abstract}

Brucellosis vaccines are designed to induce the cellular immunity. An effective brucellosis vaccine is one that could induce both cellular and humoral immunity. Serum Bactericidal Assay(SBA) is an important method for the determination of vaccine humoral immunity. This study is the first to observe humoral immunity in brucellosis by SBA. Extracted B.abortus LPS and OMP's were injected to rabbits. Group1 injected by $25 \mu \mathrm{g}$ of LPS, Group2 injected by $50 \mu \mathrm{g}$ of OMP 's and Group3 injected by $1 \mathrm{ml}$ of combined vaccine, 3 times every 2 weeks. The Groups were challenged with B.abortus 544 in the second injection. Sera were separated 2 weeks after the last injection. SBA was performed, each well was streak cultured into a plate of Brucella Agar. Colony count was done for each plate. Results have shown, the third injection of the combined vaccine, had the highest titer of $1 / 64$, and the efficacy of the vaccine was $\% 87.71$.

\section{Introduction}

The first effective vaccine against brucellosis was the live attenuated vaccine Brucella abortus S19 strain. Although this vaccine protects cattle against Brucella abortus, but its side effects has led it to be used with caution [2]. Despite these complications, the Brucella melitensis vaccine strain, Rev-1 leads to the control of brucellosis in sheep and goats, only in endemic areas [3]. Many researchers have been performed live attenuated vaccine strains. One of the first strains of Brucella abortus 45/20, which could transform back into the pathogenic form. Brucella abortus strain RB51 vaccine protects cattle against Brucella abortus and has fewer side effects [4]. The vaccine is a preventive tool, which is used to eradicate brucellosis. In the classical serological tests, the antibody or antigen against S19 and Rev-1 vaccine, is the LPS [5]. Therefore, no specific serological tests can not distinguish between animals vaccinated with S19 and Rev-1, or a naturally infection of a brucella strain, to detect the disease. Recently, mutant strains of Brucella abortus RB51 were proposed to be used in the immunization of cattle. Thus there are no effective vaccines against brucellosis in human or live stocks [6].

The major outer membrane proteins (OMPs) of Brucella spp. were first introduced in the 1980s [7]. They were soon characterized as potential immunogenic and protective antigens. They were classified according to their apparent molecular mass as group 1,36-38 KDa OMPs, group 2 porin proteins and 31-34 and 25-27 KDa OMPs which belong to the group 3 proteins [7]. The use of recombinant protein technology and monoclonal antibodies (MAbs) has shown that the major OMPs appear to be of little relevance as antigens in smooth (S) B. abortus or B. melitensis infections i.e. low or no protective activity in the mouse model of infection and low or no immunogenicity during host infection. However, group 3 proteins in particular Omp31, appear as immunodominant antigen in the course of rough (R) B.ovis infection in rams and as important protective antigen in the B.ovis mouse model of infection. The major OMP genes display diversity and specific markers have been identified for Brucella species, biovars, and strains, including the recent marine mammal Brucella isolates for which new species names have been proposed. 
The Brucella abortus LPS, compared to the Enterobacteriacae, has an unusual structure that is significant in making T-cell mediated responses [8]. It can induce $\operatorname{lgM}$ and $\operatorname{lgG}_{3}$. In addition, according to new studies, the Brucella abortus LPS can show adjuvancity [9]. Moreover, it is also a Hapten. The LPS has a crucial role in the pathogenesis of Brucella ssp., therefore, by the characteristics described above, it is likely to consider it as a qualified vaccine candidate [10].

Susceptibility of microorganisms to antimicrobial agent is often measured in vitro by measuring the inhibiting activity of growth. These measurements often do not provide sufficient information to determine the appropriate treatment of certain infections, such as endocarditis [11]. In addition, a specific $\beta$ - Lactam antibiotic, which have bactericidal activity do not have bactericidal activity for all organisms [12]. Therefore, there is a requirement for new experimental methods which have the ability to observe the bactericidal activity in optimal conditions. However, Schlichter and Mac Lean are considered as the founders of the SBA methods. They discovered the inhibitory effects of blood serum. Although, they were unable to define a criteria for characterization of bactericidal effects. In fact, Fisher completed Schlichter's path discovery. He cultured the tubes which had no visible bacterial growth [13]. However, fisher disclaimed the urge to determine the concentration levels of bactericidal effect [14]. However, there are no accepted methods for Microdilution and Macrodilution of SBA in the world. This test can be performed at any places. Although, the implementation of this technique, due to a variety of variables will be different at any laboratory. Our aim in this study was to determine the bactericidal activity of the serum induced by the potential Brucella abortus LPS and OMP's combined subunit vaccine.

\section{Materials And Methods}

\section{Strains used in this study}

Brucella abortus S99 was provided from Bacterial Cell Bank of Pasteur Institute of Iran (CSBPI) as the strain for smooth LPS extraction.

Brucella abortus RB51 was provided as a live attenuated vaccine, which was used after resuscitation, as the source of the OMP's extraction.

Brucella abortus 544 was provided by the Department of Bacteriology, Tarbiat Modares University, and used as the challenge strain for vaccine immunization in mice and rabbits.

\section{LPS extraction}

The LPS of Brucella abortus S99 was extracted and purified by a modification of the modified hot phenol method of the Westphal (1986). Phenol with $68^{\circ} \mathrm{C}$ was added to a batch cultured Brucella abortus S99, in fermentor (Novo-Paljas Netherland) and centrifugated at 2900 RPM. 4 phases had been obtained. In order to precipitate the proteins and nucleic acids, cold methanol was added to the phenolic phase, after separation. Trichloroacetic acid was then added, 0.5 grams for each liters of solution and stirred at $4^{\circ} \mathrm{C}$ for 20 minutoc $\Delta$ ftor nontrifunation tho cunornatant wac dialyzed (cut-off $=20 \mathrm{KDa}$ ) 3 times against Loading [MathJax]/jax/output/CommonHTML/fonts/TeX/fontdata.js 
distilled water for 24 hours. Then, the white precipitate accumulated inside the dialysis sack was packaged in $100 \mathrm{cc}$ vials and lyophilized [15].

\section{LPS Detoxification}

The LPS obtained was detoxified by the addition of $0.2 \mathrm{~N} \mathrm{NaOH}$ to the purified LPS, placed in $100^{\circ} \mathrm{C}$ for 2 hours. After it cooled down, the pH was to set to 7 by $0.1 \mathrm{~N} \mathrm{HCL}$. The fatty acids released by performing dialysis against distilled water for 4 days, were cleared. The dialysate (consisted of D-LPS) was then lyophilized. In order to assure LPS detoxification, quality assurance tests, such as LAL, Bradford test, and bioassay were also done [16].

\section{OMP extraction}

its weight in moisture was suspended in Tris buffer, $10 \mathrm{mM}$ (Sigma) containing ethylene diamine, tetrachloroacetic acid, $10 \mathrm{mM}$ (EDTA) W/V. The 100\% power for 4 minutes sonication was done within half a minute at $3500 \mathrm{rpm}$ at $4^{\circ} \mathrm{C}$ and was then centrifuged. Then the cell free fluid was centrifuged for 60 minutes at 42000 RPM and ultracentrifugation was done at $4^{\circ} \mathrm{C}$. the precipitate was suspended in $20 \mathrm{ml}$ sodium N-Lauryl sarcosinate \%2 added to 0.1M Tris buffer containing $10 \mathrm{mM}$ EDTA and kept in room temperature for 1 hour. It was ultracentrifuged again at 42000 RPM for 1 hour at $4^{\circ} \mathrm{C}$. The OPM's precipitated in the tube were solubilized in $15 \mathrm{ml}$ water, then dialysed against $0.2 \mathrm{M} \mathrm{NaCl}$, with three replacements every 8 hours, for 24 hours at $4^{\circ} \mathrm{C}$. the OMP's deposits in $15 \mathrm{ml}$ distilled water and against $\mathrm{NaCl} 0.2 \mathrm{M}$. The Dialysed OMP's were devided in sterile 20 and $50 \mathrm{ml}$ glass vials, after passing through $0.22 \mu \mathrm{m}$ filters and kept in $-20^{\circ} \mathrm{C}$. quality control tests were also done.

\section{Combination of the Brucella abortus LPS and OMP's}

The combined vaccine was made containing $25 \mathrm{mg} / \mathrm{ml}$ LPS and $50 \mu \mathrm{g} / \mathrm{ml}$ OMP's. $10 \mathrm{ml}$ of the vaccine mentioned was provided [17].

\section{Colony count of Mice spleens}

First, the mice were sacrificed and the spleens removed were crushed in plates containing $1 \mathrm{ml}$ saline.

The original spleen concentration was diluted $\frac{1}{10}, \frac{1}{100}$ and $\frac{1}{1000}$ and then streak cultured on brucella agar medium and incubated at $37^{\circ} \mathrm{C}$. The plates were controlled for up to 1 week. The colonies formed on the agar plate, were counted next [18].

\section{Immunization of mice and rabbits}

Five BALB/c mice were considered, and $0.2 \mathrm{ml}$ of the combined vaccine was injected to each of them, contemporarily and with the same injection program for the rabbits.

Four groups consisted of two white New Zealand rabbits were chosen. Group 1 was injected by $25 \mu$ LPS, Group 2 was injected with $50 \mu$ of the OMP's, the next group was injected with $1 \mathrm{ml}$ of the combined vaccine. The injections were done twice, with a 14 days interval. In order to simulate brucellosis in all Loading [MathJax]/jax/output/CommonHTML/fonts/TeX/fontdata.js ella abortus 544, two weeks after the first 
injection. Two weeks after the last injection, the total blood for all groups was drawn and their sera were separated, in order to perform Serum Bactericidal Assay [19].

\section{Serum Bactericidal Assay}

Serum Bactericidal Assay was performed by, serial two-fold dilution of the group's sera in DPBS; by placing $50 \mu \mathrm{L}$ DPBS in $\frac{1}{2}$ to $\frac{1}{128}$ wells (the second well in each row to the last well). The first well of each group of serum was placed by $100 \mu \mathrm{l}$ of undiluted serum. $50 \mu \mathrm{l}$ of the first well content was placed in the $\frac{1}{2}$ well and serially diluted by the same sampler tip to the $\frac{1}{128}$. Then, $50 \mu \mathrm{l}$ of $10^{5}$ Brucella abortus 544 concentrations was placed in each well as challenge [20].

The following controls were also considered:

\section{Negative serum}

$50 \mu \mathrm{l}$ Negative serum $+50 \mu \mathrm{l} 10^{5}$ Bacterial concentration (Brucella abortus 544$)+50 \mu \mathrm{l}$ DPBS

\section{Cellular Control}

$50 \mu$ inactivated Baby Rabbit Serum $+50 \mu l 0^{5}$ Bacterial concentration $+50 \mu l$ DPBS

\section{Positive Control}

$50 \mu \mathrm{l}$ Antigen (LPS) Positive Serum $+50 \mu \mathrm{l} 10^{5}$ Bacterial concentration $+50 \mu \mathrm{l}$ DPBS

\section{Complement Control}

$50 \mu$ Active serum $+50 \mu l 10^{5}$ Bacterial concentration $+50 \mu$ l DPBS

\section{Bacterial Control}

only $50 \mu \mathrm{l} 10^{3}$ Bacterial concentration

After all steps above were done, the microplate was incubated for 30 minutes in $37^{\circ} \mathrm{C}$. Then, $1 \mu \mathrm{l}$ of each well was transferred to Brucella Agar plates and streak cultured at once. Then, all plates were kept in the incubator for 72 hours at $37^{\circ} \mathrm{C}$. the colonies grown on all plates were then counted. Referring to the control plates, any plate count, less or equal to $\% 50$ of the colonies were considered as positive.

\section{Results}

\section{Results for the Mice Spleen Bacterial Count}

In order to evaluate the immunogenicity of the groups vaccinated, Brucella abortus strain 544 was Loading [MathJax]/jax/output/CommonHTML/fonts/TeX/fontdata.js 
challenge.

\section{Results for the Bactericidal Activity of sera}

Since, evaluation of the serum bactericidal activity is one of the most important vaccine immunological tests, Serum Bacterial Assay was performed on immunized animal sera, challenged by of Brucella abortus 544 challenge strain, and the result have shown, the antibody against the combined vaccine has arisen at day 45 , which is two weeks after the last vaccine injection. The positive bactericidal titre of this group was ${ }^{\frac{1}{64}}$. Stimulation of antibody against the combine vaccine was significant, compared to all groups at this time. Chart -2 shows the overall efficacy of the combined vaccine vs. the RB51 live vaccine.

Table 1 Bactericidal antibody OMP+LPS vaccines combine the first and second injection combine first injection first injection of vaccine, T2: Combine vaccine injection, L: Suicide live vaccine strain RB51 title.

\begin{tabular}{|l|c|c|c|c|c|c|c|}
\hline & $\frac{1}{2}$ & $\frac{1}{4}$ & $\frac{1}{8}$ & $\frac{1}{16}$ & $\frac{1}{32}$ & $\frac{1}{64}$ & $\frac{1}{128}$ \\
\hline T1 & + & + & + & + & - & - & - \\
\hline T2 & + & + & + & + & + & + & - \\
\hline L & + & + & + & + & - & - & - \\
\hline
\end{tabular}

\section{Discussion}

Although, the S19 and RB51 live vaccines used against brucellosis are safe, even in a few cases could cause disease in animals or humans (and personal associated with the cultivation of bacteria). In addition, by the inoculation of these vaccines, the ability to distinguish vaccinated from infected animals to microbes in natural ways is very difficult. Therefore, efforts to achieve a subunit vaccine, due to the problems of using conventional vaccines not in humans has risen; by this reason, brucellosis subunit vaccine development is one of the important research areas.

Since, a variety of protein and non-protein antigens of brucella, or a combination of them have been proposed as vaccine candidates. Induction of immunity against brucellosis; both immune responses are required, particularly cellular immunity. The characteristic of pure brucella antigen are not sufficient to induce these responses. Therefore, an effective subunit vaccine against brucellosis seems likely to be a combination of different brucella antigen [17, 21, 22].

In general, since the injection of pure LPS can induce a few antibodies, although it does not stimulate the immune system with high protection. This is due to the role of LPS as a thymus-independent antigen. The LPS was extracted from Brucella abortus S99, a smooth strain, which is used in the Pasteur Institute of Iran to produce antiaens. and this component of the vaccine, was considered as the Hapten, due to the Loading [MathJax]/jax/output/CommonHTML/fonts/TeX/fontdata.js 
stimulation of the immune system. In order to correct the flaws of this vaccine, the OMP's of Brucella abortus RB51 were used. Since, the candidates do not cause long-lasting immunity.

Attempts to develop vaccines for brucellosis have been done through the world. Despite all these efforts, no one has been able to develop an effective vaccine for the use in humans and animals with minimal side effects.

In order to develop an effective vaccine against brucellosis, now Smooth Brucella Strains:

B.abortus S19, B. melitensis Rev-1 and Rough Brucella strains: Brucella abortus RB51 are used in many countries $[21,23,24]$.

Although S19 and Rev-1 have disadvantages of causing abortions in pregnant animals and are pathogenic in humans. However, more significant problems are the production of specific antibodies against O-LPS, and cross immunity seen in the conventional serological tests using S-LPS, 9, 10 and 23. Therefore, the best strain using to develop a brucellosis vaccine is Brucella abortus RB51 which, is a rough strain and does not have the disadvantages of the S19 and Rev-1 vaccine. In addition, studies have shown that the OMP's of Brucella abortus RB51 strain are immunogenic. However, each one of them by itself is not an effective inducer of the immune system itself. However, they are all used together, they show a synergistic effect in the vaccine. In this study, all the 11 OMP's were used $[17,25,26]$.

SBA is superior to the ELISA method, because ELISA measures the antibody production that can only be achieved by a vaccine. Nevertheless, SBA, antigenicity and the serum bactericidal titers against bacteria can be achieved at the sane time, as desired. SBA was the main method for testing vaccine safety against Meningitis, and could likely be used to observe the vaccine immunity for brucellosis.

Despite the fact that Brucella is an intracellular bacterium, since the new developed vaccines are killed, it will not be a problem against the intracellular bacteria. Moreover, by the application of both LPS and the OMP's of brucella abortus, the humoral and cellular immune responses to vaccines would be significant. The colony count of mice spleen clearly demonstrated the effectiveness of this vaccine compared to the control plate. Thus, indications are that the use of these two antigens may be useful in vaccine development.

Compared to the S19 vaccine, this vaccine did not show any sign of abortion. Bioassay in mice and rabbits did not show recurrence. Moreover, this vaccine does not have the risk of transformation of rough strains to soft strains. Since, there are risks of using cattle brucellosis vaccine in human. However, by using the combination of LPS and the OMP's of brucella, it will be cleared.

\section{Conclusions}


The results in this study have shown, the LPS responses in the vaccine induced the T-cell Mediated response. The OMP's in this vaccine had acted as a carrier for the LPS and boosted the immune response more for the LPS.

Due to the economic damage that brucellosis causes in livestock, the production of meat and dairy products can hopefully be raised; regardless of any concerns.

Since, conjugation of two or more molecules can lead to better immunogenicity in humans or animals, further studies in the future could be done on the evaluation of the immunity caused by the conjugation of these two antigens by Serum Bactericidal Assay.

\section{Declarations}

\section{Acknowledgements}

We would like to thank the Pasteur Institute of Iran,

\section{Compliance with Ethical Standards}

\section{Conflict of interest}

The authors have declared that no competing interests exist.

\section{Author contributions}

All authors contributed to the study conception and design. Material preparation, data collection and analysis were performed by AA, MK, HA.MSS The first draft of the manuscript was written by AA,MSS and all authors commented on previous versions of the manuscript. All authors read and approved the final manuscript.

\section{Funding}

This research did not receive any specific grant from funding agencies in the public, commercial, or notfor-profit sectors.

\section{Ethics approval}

All procedures performed in studies involving human participants were in accordance with the ethical standards of national research committee and with the 1964 Helsinki Declaration and its later amendments or comparable ethical standards.

\section{Informed consent}

Informed consent was obtained from all individual participants included in the study 


\section{References}

1. Oliveira SC, Giambartolomei GH, Cassataro J (2011) Confronting the barriers to develop novel vaccines against brucellosis. Expert Rev Vaccines 10(9):1291-1305

2. Ashford DA et al (2004) Adverse events in humans associated with accidental exposure to the livestock brucellosis vaccine RB51. Vaccine 22(25-26):3435-3439

3. Banai M (2002) Control of small ruminant brucellosis by use of Brucella melitensis Rev. 1 vaccine: laboratory aspects and field observations. Veterinary microbiology 90(1-4):497-519

4. Olsen S, Tatum F (2010) Bovine brucellosis. Veterinary Clinics: Food Animal Practice 26(1):15-27

5. Cloeckaert A et al (2004) Development and evaluation as vaccines in mice of Brucella melitensis Rev. 1 single and double deletion mutants of the bp26 and omp31 genes coding for antigens of diagnostic significance in ovine brucellosis. Vaccine 22(21-22):2827-2835

6. Moriyón I et al (2004) Rough vaccines in animal brucellosis: structural and genetic basis and present status. Veterinary research 35(1):1-38

7. Cloeckaert A et al (2002) Major outer membrane proteins of Brucella spp.: past, present and future. Veterinary microbiology 90(1-4):229-247

8. Caroff $\mathrm{M}$ et al (2002) Structural and functional analyses of bacterial lipopolysaccharides. Microbes infection 4(9):915-926

9. Pasquevich KA et al (2010) The protein moiety of Brucella abortus outer membrane protein 16 is a new bacterial pathogen-associated molecular pattern that activates dendritic cells in vivo, induces a Th1 immune response, and is a promising self-adjuvanting vaccine against systemic and oral acquired brucellosis. J Immunol 184(9):5200-5212

10. Cardoso PG et al (2006) Brucella spp noncanonical LPS: structure, biosynthesis, and interaction with host immune system. Microb Cell Fact 5(1):13

11. Balouiri M, Sadiki M, Ibnsouda SK (2016) Methods for in vitro evaluating antimicrobial activity: A review. Journal of pharmaceutical analysis 6(2):71-79

12. Burgess DS, Hall RG II (2004) In vitro killing of parenteral beta-lactams against standard and high inocula of extended-spectrum beta-lactamase and non-ESBL producing Klebsiella pneumoniae. Diagn Microbiol Infect Dis 49(1):41-46

13. Malerczyk C et al (2004) Serum bactericidal activity of gemifloxacin versus clarithromycin against Streptococcus pneumoniae with different susceptibility to quinolones. Journal of chemotherapy 16(1):56-61

14. Paulsen VS et al (2013) Structure-activity relationships of the antimicrobial peptide arasin 1-and mode of action studies of the N-terminal, proline-rich region. PloS one, 8(1)

15. Garin-Bastuji B et al (1990) Sodium dodecyl sulfate-polyacrylamide gel electrophoresis and immunoblotting analysis of smooth-lipopolysaccharide heterogeneity among Brucella biovars related to A and M specificities. J Clin Microbiol 28(10):2169-2174 
16. Pakzad I et al (2010) Novel approach of vaccination against Brucella abortus 544 based on a combination of fusion proteins, human serum albumin and Brucella abortus lipopolysaccharides. Journal of Biological Sciences 10(8):767-772

17. Jacques I et al (1992) Protection conferred on mice by combinations of monoclonal antibodies directed against outer-membrane proteins or smooth lipopolysaccharide of Brucella. Journal of medical microbiology 37(2):100-103

18. Doyle AG et al (1992) Effect of recombinant human macrophage colony-stimulating factor 1 on immunopathology of experimental brucellosis in mice. Infect Immun 60(4):1465-1472

19. Ghasemi A et al (2013) Immune reactivity of Brucella melitensis-vaccinated rabbit serum with recombinant Omp31 and DnaK proteins. Iranian journal of microbiology 5(1):19

20. Estein SM et al (2004) Immunogenicity of recombinant Omp31 from Brucella melitensis in rams and serum bactericidal activity against B. ovis. Veterinary microbiology 102(3-4):203-213

21. Campbell G, Adams L, Sowa B (1994) Mechanisms of binding of Brucella abortus to mononuclear phagocytes from cows naturally resistant or susceptible to brucellosis. Vet Immunol Immunopathol 41(3-4):295-306

22. Diaz R et al (1968) Surface antigens of smooth brucellae. J Bacteriol 96(4):893-901

23. Biron CA (1999) Initial and innate responses to viral infections-pattern setting in immunity or disease. Curr Opin Microbiol 2(4):374-381

24. Briones $G$ et al (2001) Brucella abortus cyclic $\beta$-1, 2-glucan mutants have reduced virulence in mice and are defective in intracellular replication in HeLa cells. Infect Immun 69(7):4528-4535

25. Izadjoo MJ et al (2004) Oral vaccination with Brucella melitensis WR201 protects mice against intranasal challenge with virulent Brucella melitensis 16M. Infect Immun 72(7):4031-4039

26. Rittig MG et al (2001) Intracellular survival of Brucellaspp. In human monocytes involves conventional uptake but special Phagosomes. Infect Immun 69(6):3995-4006

\section{Figures}





\section{Figure 1}

1) The mean number of colonies per spleen for each group 2) The number of colonies combined vaccine group OMP+ LPS



\section{Figure 2}

The first column on the left side indicates the spleen colony count for pure Brucella OMP's. The second column in the middle is the spleen colony count for the Brucella OMP+LPS. The column on the right is the spleen colony count done in comparison done with the current RB51 live vaccine. 
80

70

60

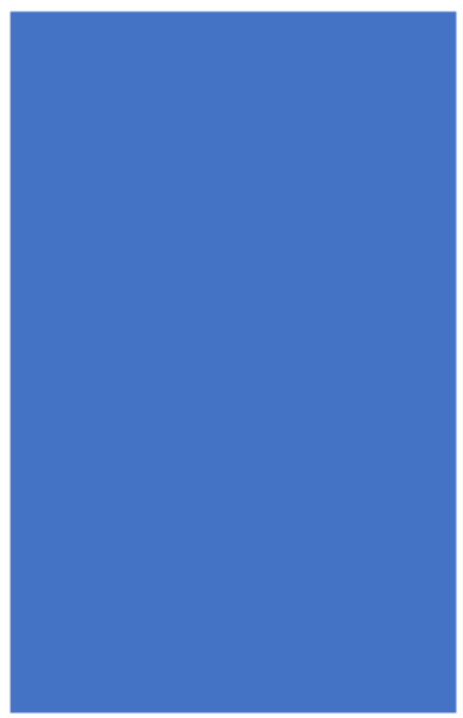

57.14

50

40

30

20

10

0



\section{Figure 3}

Percentage of subunit vaccine protects against OMP+LPS vaccine RB51: 1) The immunogenicity of combine vaccine: OMP+LPS (\%87.71) 2) The percentage of live vaccine immunogenicity RB51 (\% 57.14) 